\title{
Teaching for clinical reasoning - helping students make the conceptual links
}

\section{Wendy McMillan}

\section{Introduction}

A common complaint in dental education is that many students struggle to apply what they have learnt theoretically in the clinical context (Schmidt 1983; Masters 1989; Lowry, 1992; Graham 1996; DePaola \& Slavkin 2004; Kalkwarf et al 2005). There is a growing body of literature that argues for a relationship between conceptual thinking and clinical reasoning in trying to understand this difficulty (Rikers et al 2004; De Bruin et al 2005; Woods et al 2005; Novak et al 2006; Woods et al 2006; Auclair 2007; Woods et al 2007). The literature signals as significant for later application the way in which concepts are initially developed (Woods et al 2007), the way in which concepts are linked (De Bruin et al 2005; Novak et al 2006; Auclair 2007; Woods et al 2007), and the way in which concepts are stored for retrieval (Novak et al 2006; Auclair 2007; Woods et al 2007). The argument presented in this article draws on the literature regarding clinical reasoning and conceptual learning to highlight the kinds of learning that dental students need to do in order more easily to transfer knowledge from the theoretical to the clinical context.

The paper provides a theoretical framework for understanding how conceptual learning is achieved, and the way in which conceptual understanding influences clinical reasoning and the ability to transfer theoretical understandings to the clinical contact. From this point of departure, the paper describes teaching strategies that facilitate the kinds of learning that students need in order to develop conceptual understanding and to be able to transfer knowledge from the theoretical to the clinical context. The value of concept mapping as a strategy for assisting the development of conceptual understanding, and for facilitating later transfer, is highlighted. The paper makes a specific contribution to dental education in that it extrapolates understandings about conceptual learning, concept mapping and clinical reasoning from the medical and higher education contexts and facilitates application of these concepts in dental education. However, insights from the paper will have general applicability to other fields of health sciences education since the paper highlights the role that conceptual understanding plays in the transfer of preclinical knowledge to the clinical application context. 


\section{Understanding conceptual development}

A concept is an encapsulation of ideas that are attributable to a single class or grouping - what Simon et al (2004) describe as "a mental object" or "a cognitive entity". Conceptual understanding implies knowledge of an idea, and how it relates to already acquired ideas (Suaalii \& Bhattacharya 2007). It requires an understanding of the contexts within which the idea is applicable, as well as its limitations (Suaalii \& Bhattacharya 2007). Conceptual development is hierarchical, with new concepts or concept meanings subsumed under broader, more inclusive concepts (Novak \& Gowin 1984). Novak and Gowin (1984) highlight the significance of "propositional relationship(s)" between concepts. Propositional relationships are the explicit connections that are generated between concepts (Novak \& Gowin 1984). At the most simple, two concepts might be connected with a linking word to form a proposition. Thus "sky is blue" (Novak \& Gowin 1984) indicates a valid proposition between the concepts "sky" and "blue".

\section{Conceptual development and clinical reasoning}

At a more complex level, propositions signal causal relationships between concepts (Novak \& Gowin 1984) - for example, the causal relationships between biomedical concepts (ie, the basic mechanisms and functioning of the human body) and clinical concepts (ie, the signs, symptoms and associated findings of disease) (Woods et al 2007). Rehder and Hastie (2001) argue that the power of causal theories lies in their ability to provide connections between features. In the medical context, Woods et al (2007) suggest that causal connections between basic science concepts and categories of disease contribute to the construction of "illness scripts" (Schmidt et al 1990). Illness scripts are the individual theoretical frameworks of disease that clinicians construct. They are the causal theories that provide the relationships between biomedical concepts and clinical concepts. Illness scripts contain "enabling conditions" (ie, features associated with acquisition of the illness), a description of what is not functioning (ie, the "fault"), the signs and symptoms that arise due to the fault (ie, the "consequences"), and are built up through extensive contact with multiple patients with similar symptoms (Schmidt et al 1990). Bransford et al (1999) argue that when students are provided with the conceptual building blocks for such frameworks and when they are encouraged to explicitly construct and articulate connections between these concepts, knowledge transfer is enhanced.

Auclair (2007) provides an explanation of why this is so. Most problems, including those of clinical diagnosis, are ill-structured (Auclair 2007). Information required to solve a problem of clinical diagnosis needs to be 
organized into patterns so as to produce sense (Auclair 2007). Auclair (2007) suggests that this ordering (in other words, the problem formulation) is simply the structuring of concepts linked by understandings of their relationships. In this way, a 'model' of a case is generated. Case generation involves the establishment of causal propositions between incoming clinical information and existing clinical and biomedical concepts. Using endocarditis as a case example, Auclair (2007) explains how expert clinicians link conceptual knowledge about bacteremia, valvular disease and embolic phenomena in causal relationships that have diagnostic utility value. The way in which the clinical problem is formulated - in other words, the way in which information regarding the patient problem is organized and linked to both existing and incoming information - allows the clinician to 'recognise' the case as belonging to a 'theory' of (in this case) endocarditis. Auclair (2007) argues that it is the similarity between the concepts and their relationships in both the case and the theory that allows clinicians to recognise that they are indeed similar. Choosing which are the most pertinent concepts to pay attention to may thus be the most important aspect in effective diagnosis.

The development of appropriate (and correct) concepts and the establishment of appropriate causal relationships between them are central to effective clinical reasoning. It is these concepts, and their subsequent conceptual networking in the context of extensive and repeated exposure to multiple patients with similar symptoms, that results in competent diagnosis (Rikers et al 2004; Woods et al 2005; Novak et al 2006; Woods et al 2006; Auclair 2007; Woods et al 2007). Teaching and curriculum planning in dental education can make a contribution to all three of these aspects - the development of basic concepts, opportunities to network concepts, and extensive and repeated exposure to multiple patients with similar symptoms.

\section{Implications for teaching and learning}

Learning is the inborn mental ability and tendency in humans to create records of experience, to sort and compare records, to identify patterns, and thus to establish concepts (Von Glasersfeld 1995). In order to reason, plan and make good decisions, an individual must be able to generalize what has been learnt in the past to new learning, and be able to apply and extend this learning to a range of situations (Haskell 2001).Transfer - the application of learning acquired within a certain task, situation, or context to another, different task, situation, or context (Murphy \& Tyler 2005) - is at the heart of being able to generalize from one situation to another. Transfer is achieved through the process of "mindful abstraction" (Salomon \& Perkins 1989) - extracting what is "central, essential or generic" (MacLellan 2005) from a context and creating a mental representation 
of these attributes (MacLellan 2005). These "units of representation" (Carey 1992) encapsulate concepts. Conceptual thinking involves creating and using these "units of representation" (Carey 1992). In the context of clinical reasoning, these "units of representation" (Carey 1992), from the apparently unrelated sources of basic sciences, laboratory contexts, and previous patient encounters, are recalled when a new patient is encountered - for example, when a dentist recognizes the potential relationship between a reported sore throat and HIV infection (see Figure 2).

The process of "mindful abstraction" (Salomon \& Perkins 1989) is active, rather than automatic (Salomon \& Perkins 1989). It is achieved through the conscious decisions that people make to use particular strategies to solve new problems (Salomon \& Perkins 1989), either because the strategies appear to present themselves on relevant occasions (MacLellan 2005) or because the individual deliberately searches for and retrieves previously learned strategies for potential application in new situations. It is only the learner who can achieve this abstraction and application (MacLellan 2005).

However, generating, recalling and using "units of representation" (Carey 1992) requires deliberate practice. While experts recognize the constellation of signs and symptoms and almost automatically infer associated encapsulated concepts and so form a diagnosis (Rikers et al 2004), students need opportunities first to develop the concepts and conceptual frameworks (see for example, Figure 1) and then opportunities to apply these conceptual frameworks in the clinical context (see Figure 2). Opportunities need to be created for extensive and repeated exposure to multiple patients with similar symptoms (Rikers et al 2004; Woods et al 2005; Novak et al 2006; Woods et al 2006) - as for example, in Figure 2, students need exposure to patients with sore throats with a variety of associated causes (for example, HIV infection, malignancies, immune compromised elderly) in order for them to understand the diagnostic contexts within which their particular conceptual frameworks are applicable, and where these frameworks have potential limitations (Suaalii \& Bhattacharya 2007). Practice is understood to be deliberate because it involves the deliberate, conscious effort of a learner in concept development, in concept application (ie, in clinical diagnosis), and in monitoring one's own understanding of the actual process of applying prior knowledge to the 'new' clinical context (Bereiter \& Scardamalia 1989). In the clinical context, the teacher facilitates this development by making overt the clinical reasoning process and by helping novice clinicians to understand their thinking processes in action (Mandin et al 1997; Eva 2004; Kuiper \& Pesut, 2004; Bowen 2006; Novak et al 2006). 
Because of the interplay between theoretical learning and clinical application in the development and networking of concepts, the teacher's role is fulfilled both in the classroom and the clinical context (Ramani 2003). It is in the classroom where basic concepts - whether bio-psycho-social or medical - are developed and where initial connections between them are forged. Conceptual development is facilitated when learners are actively involved in their own learning process through opportunities to generate hypotheses, interpret data, and challenge and affirm constructs which are viewed, within particular disciplines, as appropriate ways of interpreting the world (Perkins \& Salomon 1994; MacLellan 2005; Billing 2007; Suaalii \& Bhattacharya 2007). Even given an appropriate learning environment, there are, however, students who still struggle to extract the essence from the detail and tend to miss the core concepts and their essential relationships in the welter of background information to which they are exposed - whether this is through formal input from teachers or when engaged in problem-based learning or evidenced-based medical literature searches (Reilly 2007).

Teachers can help these students learn by making "an explicit effort to help students understand knowledge structure and production" (Novak \& Gowin 1984). One way in which this can be achieved is through the strategy of "concept mapping" (Novak \& Gowin 1984). Concept maps are intended to represent meaningful relationships between concepts in the form of propositions (Novak \& Gowin 1984; All \& Havens 1997; Gaines 1999; All et al 2003; Clayton 2006). Both the concepts and the "linking words" signifying the propositional relationships between concepts are recorded on the concept map (Novak \& Gowin 1984). This strategy allows students to work out what is core and what is not, what is centrally significant to new learning, and how new learning relates to existing knowledge (All \& Haven 1997; Gaines 1999; All et al 2003; Clayton 2006). Figure 1 illustrates a concept map of the relationship between leukoplakia and HIV infection that might be generated by a student. In this example, the boxes represent the concepts and the elipses the connections that the student perceives between the concepts.

Figure 1

A student's concept map of the relationship between leukoplakia and HIV infection 


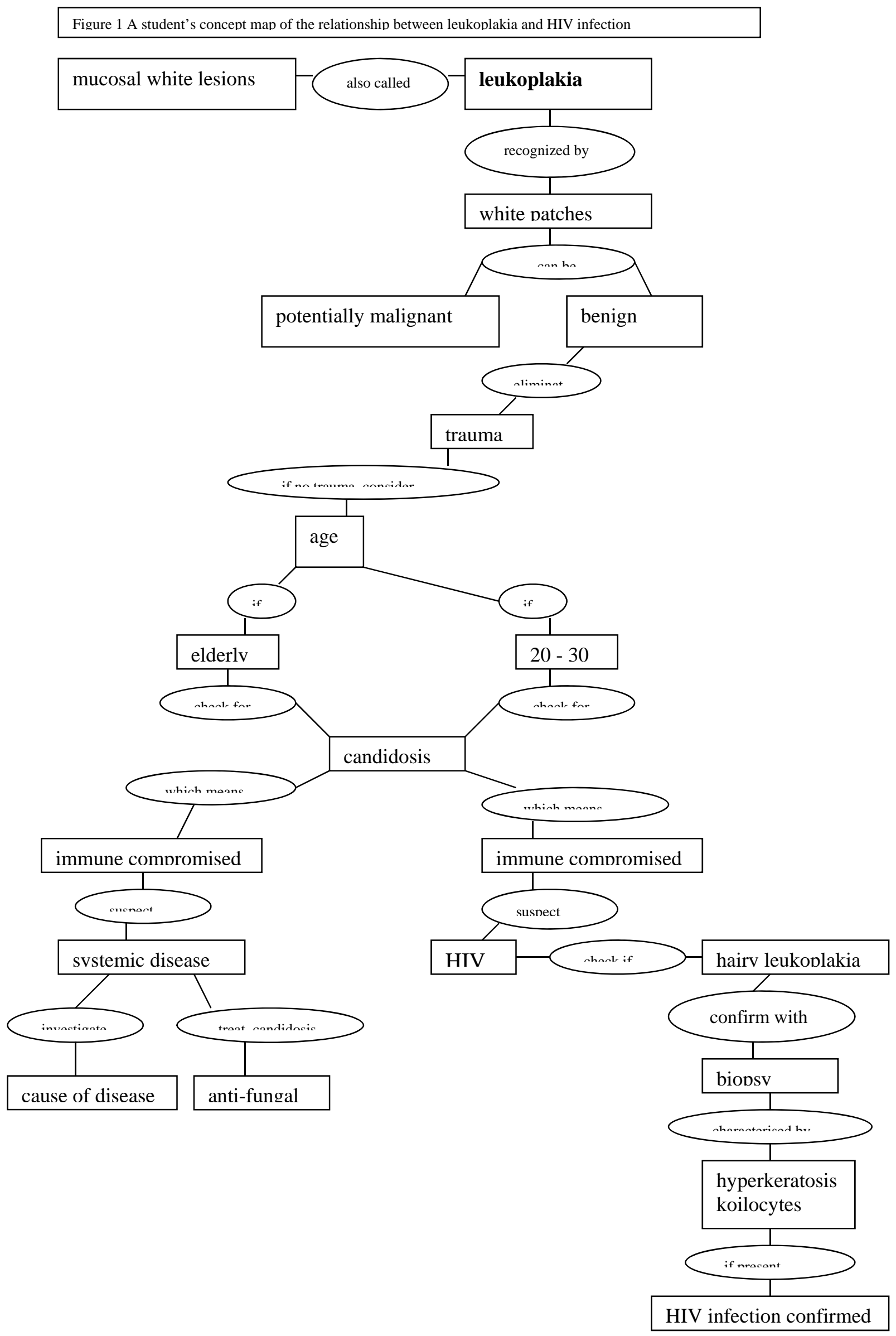


As is evident from the example, concept maps differ from traditional mindmapping in the explicitness with which the connections between concepts are recorded (Mahler et al 1991; Jonassen et al 1993; Plotnick 1997; Novak 1998; Chularut \& DeBacker 2004; Clayton 2006; Hay et al 2008; Novak \& Canas 2008). Indeed, Novak and Gowin (1984) argue that the power of concept mapping as a learning and teaching tool lies in this recording since it allows for the development of an understanding of the relationships among different bits of information (All \& Haven 1997; Baugh \& Mellott 1998; Mueller et al 2002; All et al 2003), and provides opportunities to build on previous knowledge and skills (Baugh \& Mellott,1998; Dobbin,2001). A study of the example illustrated in Figure 1 demonstrates this claim. This student was required not only to identify core concepts related to both leukoplakia and HIV infection, but also to 'explain', through the relationship elipses, their connections. It is in making these connections that students actually come to understand the complex relationships between the various things that they have already learnt, as well as the relationship between this knowledge and new information. Without the connections, it is easy for a student to make a list of terms without really understanding their significance or their inter-relatedness. Only in making the explicit linkages is the student forced to think about what information is needed, how it needs to be organized and sequenced, and how it fits together.

Concept maps act, thus, as important diagnostic tools for teachers. Novak and Gowin (1984) highlight that concept maps are powerful tools for observing the nuances of meaning a student holds for the concept embedded in his or her map. When concept maps are diligently constructed, they are powerful revealers of students' cognitive organization (Novak \& Gowin 1984). Faulty conceptions and linkages are easily identified and can then be addressed by the teacher. To illustrate this point, imagine that a student submitted Figure 1 without any of the connecting elipses. The experienced clinician-teacher would furnish those connections unconsciously and assume that the student understood the relevant concepts and their relationships. However, what if the concept map was submitted and all the elipses had been replaced with "is"/"are" - a connecting term that was deemed perfectly appropriate for the proposition "the sky is blue" discussed earlier in this paper. While many of these propositions may read as 'true', their relevance to the larger clinical problem may be irrelevant, or even incorrect. Clearly such a student does not understand the significance of the concepts with specific regard to leukoplakia and HIV infection.

The strategy of concept mapping can valuably be applied at multiple points in the student's learning. The teacher might generate the concept map, illustrating the nature of the relationships, when new concepts and embedded knowledge are 
being introduced. Concept mapping can be used for tutorial activities where students are explicitly asked to track the connections between new concepts and embedded knowledge, and for clinical 'paper cases' where students establish causal propositions between incoming clinical information and existing clinical and biomedical concepts. Students can use the strategy both during initial learning and when revising. Given the diagnostic characteristic of concept maps, they also make excellent assessment activities (Norman 2008). Students might be asked to illustrate relationships between biomedical concepts and clinical concepts.

Finally, concept maps have potential application in the clinical context. Figure 2 shows a concept map that might be generated by a clinical teacher to illustrate a point of diagnosis to a student in the clinical context. The concept map deals with a particular patient, and contextualizes diagnostic steps and strategies.

Figure 2

Concept map of specific diagnostic process 


\section{patient with sore throat}

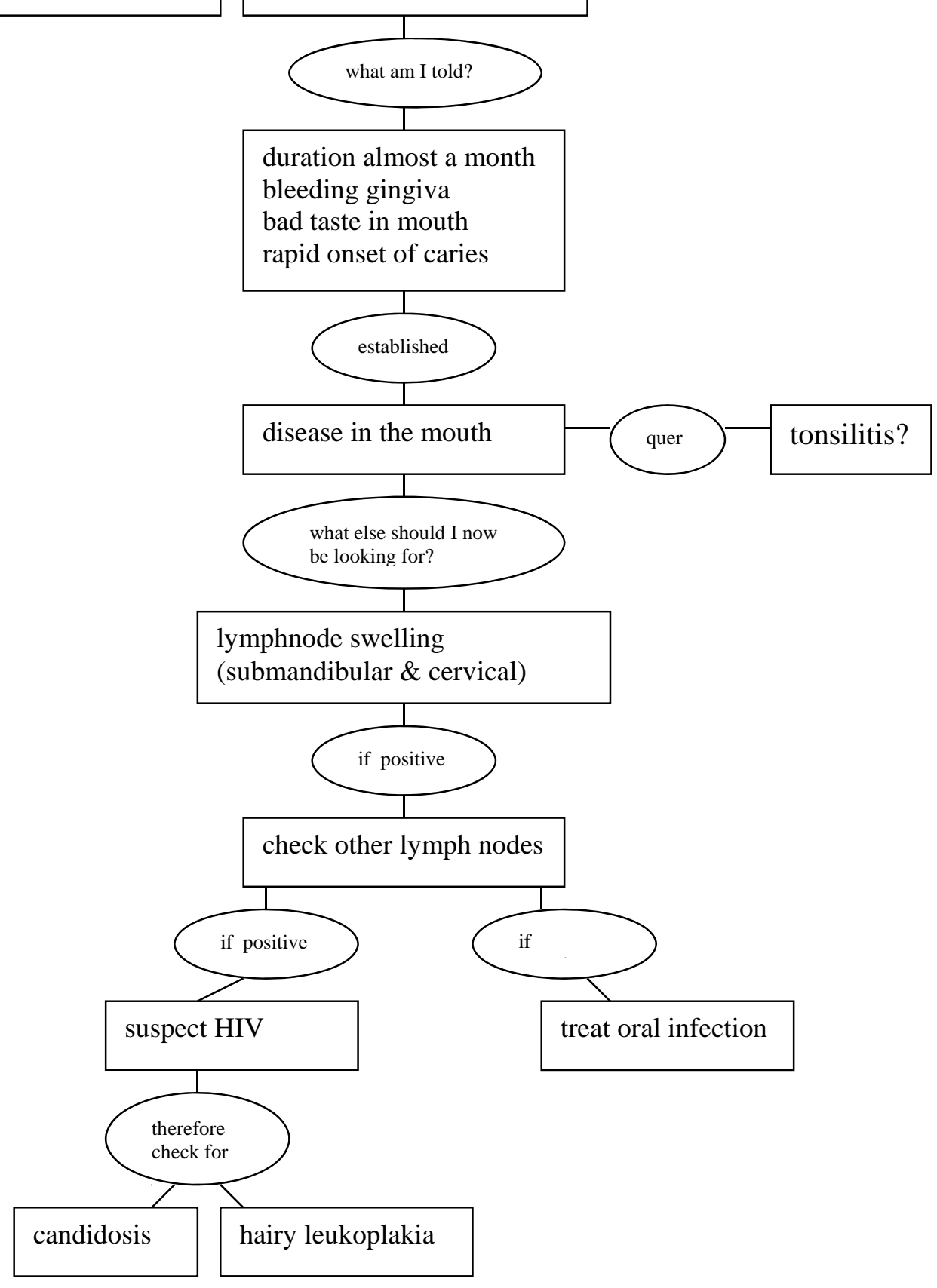


Students seldom get a chance in the clinical context of seeing and hearing the thinking steps that experienced clinicians go through when engaged in the diagnostic process. Illustrating this process for students through the use of a concept map makes overt the clinical reasoning process and helps novice clinicians understand their thinking processes in action (Mandin et al 1997; Parsell \& Bligh 2001; Ramani 2003; Eva 2004; Irby \& Bowen 2004; Kuiper \& Pesuit 2004; Novak et al 2006; Bowen 2006; Norman 2006; Reilly 2007). In this way clinical teachers help students establish connections between previous learning and a particular clinical presentation.

Three strategies for helping students establish such connections are suggested in the literature. Firstly, clinical teachers can demonstrate the clinical reasoning process, articulating their own problem representations to model the type of abstract summary they expect from students (Irby \& Bowen 2004; Bowen 2006; Reilly 2007). This strategy provides an opportunity for the teacher to reason aloud, linking the abstractions to existing illness scripts (Bowen 2006). Through reasoning aloud activities, clinical teachers highlight the way in which clinicians seek appropriate diagnostic possibilities in the patient history and physical examination (Bowen 2006). By exposing the ambiguity and ambivalence inherent in clinical reasoning (Reilly 2007) and admitting their own lack of knowledge (Ramani 2003), clinical teachers set the tone for students to admit their limitations and to ask questions.

Secondly, clinical teachers can elicit clinical reasoning from learners (Parsell \& Bligh 2001; Ramani 2003). The clinical teacher might help students to identify what information is required for care of the patient (Irby \& Bowen 2004). Learners can be prompted to generate a single sentence summary of the case with the use of appropriate medical terms (Bowen 2006; Norman 2006), and to prioritise a diagnosis through comparing and contrasting potential diagnoses with the actual clinical data (Bowen 2006). In providing opportunities for learners to think about the relationship between clinical findings, biomedical knowledge and relevant diagnoses (Bowen 2006), these activities promote the development of illness scripts

Finally, clinical teachers can listen - without interrupting - while students reason spontaneously (Ramani 2003; Irby \& Bowen 2004). This activity allows the teacher to understand how the student has organized the case in his or her own mind, to identify the learner's understanding of the case, and to distinguish gaps in knowledge or errors in reasoning that can become the focus of teaching 
(Irby \& Bowen 2004; Reilly 2007). Any of these strategies might be facilitated through the drawing of concept maps since the map provides a reference point for discussion. The teacher, whether in the theoretical or clinical context, thus has a significant role to play in providing an appropriate learning environment.

\section{Conclusion}

Drawing on the assumption that a relationship exists between conceptual thinking and clinical reasoning, this paper has outlined a theoretical framework for understanding how conceptual learning is achieved and the way in which conceptual understanding influences clinical reasoning and the ability to transfer theoretical understandings to the clinical context. This theoretical framework signaled ways to assist students to develop the conceptual understanding prerequisite for application in the clinical context. Effective clinical reasoning depends on the amount of knowledge and its coherence, the linkages networking the knowledge, and frequent opportunities to use the knowledge so as to refine it (Grant \& Marsden 1987). The argument presented in the paper suggests that an emphasis on conceptual learning has the potential to facilitate the development of clinical reasoning. Helping students to map their understandings in the basic sciences and pre-clinical context contributes to the development of conceptual frameworks that can be transferred to the clinical context. Assisting students to retrieve these conceptual frameworks and apply them appropriately is the challenge of clinical teaching. The emphasis in the clinical context is on making overt the clinical reasoning process and helping novice clinicians understand their thinking processes in action. Concept mapping has the potential to assist the development of clinical reasoning as the mapping of relationships between concepts facilitates transfer of insights between basic science and clinical contexts.

\section{Acknowledgements}

The author wishes to thank Professor Vincent Phillips for his assistance with the content of the concepts maps, Figure 1 and Figure 2. 


\section{References}

All AC, Huycke LI. \& Fisher, M. J. 2003. Instructional tools for nursing education: Concept maps. Nursing Education Perspectives 24:311-317.

All AC, Havens RL. 1997. Cognitive/concept mapping: A teaching strategy for nursing. Journal of Advanced Nursing 25:1210-1219.

Auclair F. 2007. Problem formulation by medical students: an observation study. BMC Med Educ 7:16.

Baugh NG, Mellott KG. 1998. Clinical concept mapping as preparation for student nurses' clinical experiences. Journal of Nursing Education 37:253256.

Bereiter C, Scardamalia M. 1989. Intentional learning as a goal on instruction, in: L Resnick (Ed.) Knowing, learning and instruction (New Jersey, Lawrence Erlbaum).

Billing D. 2007. Teaching for transfer of core/ key skills in higher education: Cognitive skills. High Educ 53:483-516.

Bowen JL. 2006. Educational strategies to promote clinical diagnostic reasoning. New England Journal of Medicine 355:2217-2225.

Bransford JD, Brown , Cocking R. 1999. How people learn: Brain, mind, experience and school (Washington, DC, National Academy Press).

Carey S. 1992. The origin and evolution of everyday concepts, in RN Giere (Ed.) Minnesota studies in the philosophy of science: Cognitive models of science (Minneapolis, University of Minnesota Press).

Chularut P, Debacker TK. 2004. The influence of concept mapping on achievement, self-regulation, and self-efficacy in students of English as a second language. Contemporary Education Psychology 29:248-263.

Clayton L. 2006. Concept mapping: An effective, active teaching-learning method. Nursing Education Perspectives 27:197-203.

De Bruin ABH, Schmidt HG, Rikers RMJP. 2005. The role of basic science knowledge and clinical knowledge in diagnostic reasoning: a structural equation modeling approach. Academic Medicine 80:765-773. 
De Paola DP, Slavkin HC. 2004. Reforming dental health professions education: A white paper. J Dent Educ 68:1139-1150.

Dobbin KR. 2001. Applying learning theories to develop teaching strategies for the critical care nurse. Critical Nursing Clinics of North America 13:1-11.

Eva KW. 2004. What every teacher needs to know about clinical reasoning. Med Educ 39: 98-106.

Gaines C. 1999. Clearing up the "concept fog”. ABNF Journal 10:52-53.

Graham CL. 1996. Conceptual learning processes in physical therapy students. Phys Ther 76:856-866.

Grant J, Marsden P. 1987. The structure of memorized knowledge in students and clinicians: an explanation for diagnostic expertise. Med Educ 21:9298.

Haskell R. 2001. Transfer of learning (London, Academic Press).

Hay D, Kinchin I, Lygo-Baker S. 2008. Making learning visible: the role of concept mapping in higher education. Stud High Educ 33:295-311.

Irby DM, Bowen J L. 2004. Time-efficient strategies for learning and performance. The Clin Teach 1:23-28.

Jonassen D, Beissner K, Yacci M. 1993. Structural knowledge: Techniques for representing, conveying and acquiring structural knowledge (Hillsdale, NJ, Erlbaum).

Kalkwarf KL, Haden NK, Valachovic RW. 2005. ADEA commission on change and innovation in dental education. J Dent Educ 69:1085-1087.

Kuiper RA, Pesuit DJ. 2004. Promoting cognitive and metacognitive reflective reasoning skills in nursing practice: self-regulated learning theory. Issues and innovations in nursing education 45:381-391.

Lowry S. 1992. What's wrong with medical education in Britain? BMJ 305:12771280. 
MacLellan E. 2005. Conceptual learning: The priority for higher education. British Journal of Educational Studies 53:129-147.

Mahler S, Hoz R, Fischl D, Tov-Ly E, Lernau OZ. 1991. Didactic use of concept mapping in higher education: application in medical education. Instruct Sci 20:25-47.

Mandin H, Jones A, Woloschuk W, Harasym P. 1997. Helping students learn to think like experts when solving clinical problems. Academic Medicine 72:173-179.

Masters G. 1989. Improving the assessment of clinical reasoning, in: J I Balla, M Gibson \& AM Chang (Eds.) Learning in medical school. A model for the clinical professions (Hong Kong, Hong Kong University Press).

Mueller A, Johnston M, Bligh D. 2002. Joining mind mapping and care planning to enhance student critical thinking and achieve holistic nursing care. Nursing Diagnosis 13:24-27.

Murphy SM, Tyler S. 2005. The relationship between learning approaches to part-time study of management courses and transfer of learning to the workplace. Educational Psychology 25:455-469.

Norman G. 2006. Building on experience - the development of clinical reasoning. New England Journal of Medicine 355:2251-2252.

Novak JD, Gowin DB. 1984. Learning how to learn (Cambridge, Cambridge University Press).

Novak JD, Canas AJ. 2008. The theory underlying concept maps and how to construct and use them Available: http://cmap.ihmc.us/Publications/ResearchPapers/TheoryUnderlyingCo nceptMaps/pdf (accessed 17 October 2009).

Novak JD. 1998. Learning, creating and using knowledge: concept maps as facilitative tools in schools and corporations (Hillsdale, NJ, Erlbaum)

Novak K, Mandin H, Wilcox E, Mclaughlin K. 2006. Using a conceptual framework during learning attenuates the loss of expert-type knowledge structure. BMC Med Educ 6:37-44. 
Parsell G, Bligh J. 2001. Recent perspectives on clinical teaching. Med Educ 35:409-414.

Perkins DN, Salomon G. 1994. Transfer of learning, in: $\mathrm{T}$ Husen \& $\mathrm{T}$ Postlethwaite (Eds.) The international encyclopedia of education (Oxford, Elsevier/ Pergamon).

Plotnick E. 1997. Concept mapping: a graphical system for understanding the relationship between concepts. ERIC Digest (ERIC Clearinghouse on Information and Technology, Syracuse, NY. Eric Identifier, ED407938).

Ramani S. 2003. Twelve tips to improve bedside teaching. Med Educ 25:112-115.

Rehder B, Hastie R. 2001. Causal knowledge and categories. The effects of causal beliefs on categorization, induction, and similarity. Journal of Experimental Psychology - General 130:323-360.

Reilly BM. 2007. Inconvenient truths about effective clinical teaching. The Lancet 370: 705-711.

Rikers RMJP, Lovens SMM, Schmidt HG. 2004. The role of encapsulated knowledge in clinical case representations of medical students and family doctors. Med Educ 38:1035-43.

Salomon G, Perkins D. 1989. Rocky roads to transfer: rethinking mechanisms of a neglected phenomenon. Educational Psychologist 24:113-142.

Salvucci DD, Anderson JR. 2001. Integrating analogical mapping and general problem solving: The path-mapping theory. Cog Sci 25:67-110.

Schmidt HG. 1983. Problem-based learning: rationale and description. Med Educ17:11-16.

Schmidt HG, Norman GR, Boshuizen HPA. 1990. A cognitive perspective on medical expertise: theory and implications. Academic Medicine 65: 611621.

Simon MA, Tzur R, Heinz K, Kinzel M. 2004. Explicating a mechanism for conceptual learning: elaborating the construct of reflective abstraction. Journal for Research in Mathematics Education 35:305-329. 
Srinivasan M, Mcelvany M, Shay JM, Shavelson RJ, West DC. 2008. Measuring knowledge structure: Reliability of concept mapping assessment in medical education. Academic Medicine 83:1196-1203.

Suaalii F, Bhattacharya M. 2007. Conceptual model of learning to improve understanding of high school chemistry. Journal of Interactive Learning Research 18:101-110.

Torree DM, Daley B, Stark-Schweitzer T, Siddattha S, Petkova J, Ziebert M. 2007. A qualitative evaluation of medical student learning with concept maps. Med Teach 29:949-955.

Von Glasersfeld E. 1995. Radical constructivism: A way of knowing and learning (Washington, DC, Falmer)

Woods NN, Brooks LR, Norman GR. 2007. It all makes sense: biomedical knowledge, causal connections and memory in the novice diagnostician. Advances in Health Science Education 12:405-415.

Woods NN, Howey EHA, Brooks LR, Norman GR. 2006. Speed kills? Speed, accuracy, encapsulations and causal understanding. Med Educ 40:973979.

Woods NN, Brooks LR, Norman GR. 2005. The value of basic science in clinical diagnosis: creating coherence among signs and symptoms. Med Educ 39:107-112. 